\title{
Research into the Development Pattern of Vocational Education on Medical Instruments in Internationalization
}

\author{
Li WANG \\ University of Shanghai for Science and Technology, Shanghai, China \\ Yuewei Ding, Xin Zhang, Yihong Fu \& Hong Chen \\ Shanghai Medical Instrumentation College, Shanghai, China
}

\begin{abstract}
Authors of this paper try to put forward the strategic development pattern of higher vocational education based on the ecological Niche Theory, and they find the important four dimensions of this pattern are "college-enterprises cooperation", "work-integrated learning", "international cooperation" and "production learning and research applying". They design the research model of the higher vocational education for medical instruments in internalization and analyze the implementing results in Shanghai Medical Instrumentation College. At last, they have summed up a lot of useful theoretical suggestions and practical experience which are helpful to establish the consummate and effective modern vocational education system of China..
\end{abstract}

KEYWORD: Higher Vocational Education; Niche Theory; College-enterprises cooperation; International cooperation; Production learning and research applying

\section{INTRODUCTION}

Chinese Higher Vocational Education (HVE) has made significant progress in recent years, during which the operating mechanism of collegeenterprises cooperation and work-integrated learning was invented. But technical education in China is relatively weak and is in urgent need of a large amount of technical personnel who can not only begin to practice, but also can tackle key technical problems and make technical innovation. In this new historical period, the HVE on medical instruments have to confront with this challenge and undertake the historical task of promoting the national transformation and upgrading of the economy, the medical instruments technique. We think that the research on the strategic development pattern of HVE based on the ecological Niche Theory(NT) is useful to explore international development path for HVE on medical instruments and is helpful to accumulate some experience of HVE in the context of internationalization.

\section{STRATEGIC DEVELOPMENT PATTERN OF HVE}

\subsection{College-enterprises cooperation and work- integrated learning}

Employment has been put in an extremely important status with the thought of teaching and cultivating of
HVE being updated in order to link education and employment together. For college of HVE, collegeenterprises cooperation and work-integrated learning become a key point in their development pattern that is not only a direction of running a college but also a basis of development. Main target of HVE is to Cultivating students for the first line of producing, service and management who are practical talents being in urgent need. college-enterprises cooperation and work-integrated learning can be an effective ways to strengthen the practice teaching and can improve the quality of teaching well[1].

The college can share the resources with enterprises for cultivating talents, which are needed by society, and producing win-win situations through the cooperation for college, enterprises, students and society.

\subsection{Opportunities and challenges facing HVE}

At present, the development situation of economic globalization and integration of science and technology led the world market competition intensified with Chinese accession to the WTO and the deepening of reform and opening-up, and how to cultivate talents of highly skilled personnel was focused on because of the advent of the era accompanied by knowledge economy. Technological progress, industrial upgrading and innovation driven have become the biggest opportunities and challenges facing HVE[2]. 
The medical instruments industry grow so rapidly and their product upgrade so fast that it turn the "Twelfth five-year" period into a important point for transformation and upgrading of medical instruments in china. As far as the opportunities and challenges facing HVE concerned, more and more peoples are studying on strategic development pattern for medical instruments too.

\section{DEVELOPMENT PATTERN OF HVE BASED ON NT}

\subsection{Instructions of Niche}

Niche Theory means that all kinds of creatures have their own "niche" in nature. Here niche includes two aspects, one is its ecological environment, the other one is the ecological environment that they need. Niche phenomenon is universal to all life phenomenon. We should think of the Niche of HVE from their background they are relying on and their developing trend which is the most dynamic, strongest vitality and the most promising choice. It also can play a role and give us a great meaningful help when we design and research the strategies of HVE of development and competition based on NT nowadays.

\subsection{Niche elements in HVE}

Higher vocational colleges played an important roles in promoting the country's economic development and in the promotion of mass higher education in China. It has a unique and irreplaceable nature of its field. Therefore, higher vocational college should have a variety of social functions, mainly manifests itself in two ways: one is to promote the development of education, the second is to serve local economic and social development[4]. Every function orientation of higher vocational colleges had a profound impact on its survival and development. Throughout the development of higher vocational education under the background of economic law, we build careers, education, technical services as the three elements of construction of higher vocational education niche (as shown in Figure 1).

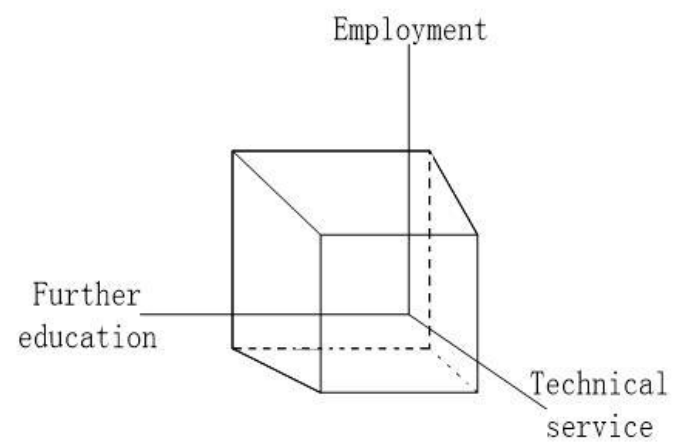

Figure 1. schematic diagram of niche structure of HVE.

\subsection{Development pattern of HVE on medical instruments in internationalization}

Based on the new situation of higher vocational education facing the challenges and opportunities face of the industry trends, international personnel training needs, development of higher vocational education of law and science of constructing modern vocational education system development plan, according to law of niche, we offer medical devices development of higher vocational education under the background of internationalization strategy model construction (as shown in Figure 2).

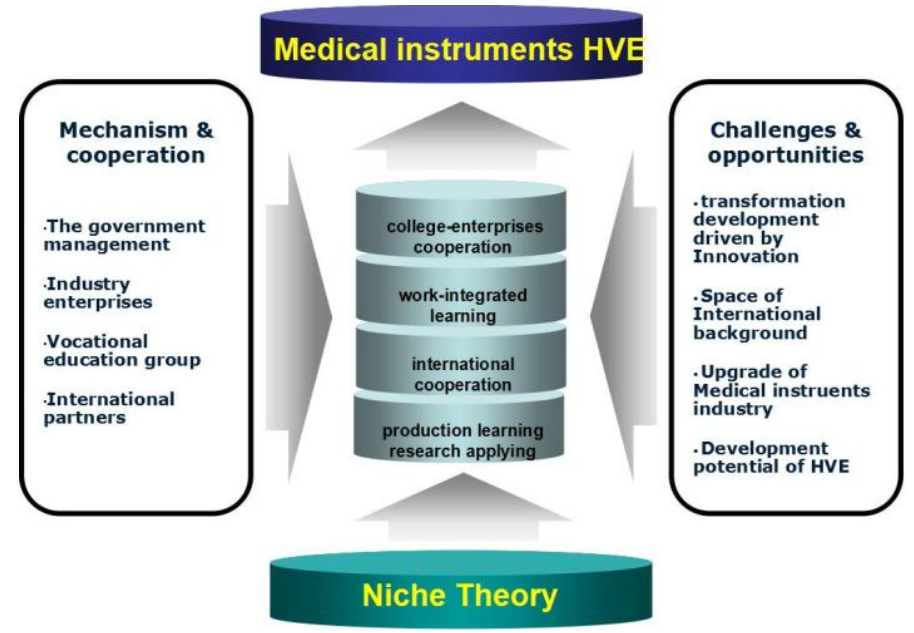

Figure 2. construction of development pattern of HVE on Medical Instruments in Internationalization.

First of all, cooperation between schools and enterprises, and work-integrated learning is a major vocational education talents training mode. It embodies the characteristics of vocational education in their own, it is effective way of training skilled talents and advantages of mutual and features of higher vocational education [6].

Second, globalization, internationalization of human resources becomes the core of demand trends and competition. Become an inevitable trend of internationalization of HVE. International cooperation project has helped to develop an international perspective, highly skilled personnel. International cooperation determines the degree of international cooperation the international competitiveness of HVC, it is very important for the future development.

Thirdly, the decision of the State Council on accelerating the development of modern vocational education(State (2014) 19th-encouraging vocational education activity, accelerate the construction of modern vocational education system), point out that integration of industry, education is the core nature of modern vocational education system, the most important of the soul, the root path of building modern vocational education system. In combination with industry, schools and scientific research further emphasis on applications and users, highlighting the 
combination must be based on enterprises as the main body, to be market-oriented. And with topnotch innovative talents with high skills in it, is the work of talents cultivation of higher vocational education is an important strategic choice.

\subsection{Discussion}

Then we should deal easily with economic and social problems of technological progress, industrial upgrading and innovation driven if we could combine college-enterprises cooperation, workintegrated learning, international cooperation and production learning and research applying with college development and implement the strategic development planning.

Only in this way can we promote the healthy development of HVE well and can we perfect the model for modern vocational education system scientifically.

\section{IMPLEMENTING AND OPERATING}

\subsection{SMIC}

Shanghai Medical Instrumentation College (SMIC) was founded by the Ministry of Health in 1960, and It has irreplaceable functions of cultivating scarce high-skilled medical device talents for China, so the practice process of this development pattern has its characteristics of representative and generalization.

\subsection{The good results}

SMIC pay attention to the internationalization of vocational education clearly and take it as strategic point of the new round of the development. SMIC has specific cooperation projects with more than 20 countries and regions up to now, for example Osaka Japan jikei academy, northeastern university in the United States, Hochschule Furtwangen University, Victoria university of Australia etc. In last five years, 309 students from SMIC have already gone abroad for further study and the number of the exchange students from overseas universities to SMIC has reached 426.

The cooperation through international cooperation is not only among overseas universities, but also among medical instruments supplying chains of overseas multinational companies or enterprises, like Berchtold Germany and Stryker USA, etc. So the international cooperation members of this chain could cooperate to enhance their competitive ability and to win a reputation for China's HVE in the world too.

Within the college and enterprises and industry, SMIC has achieved real economic cooperation. It is featured with outstanding combination of medical and industrial fields, cooperation of college and enterprises. It follows closely the needs of medical device industry. SMIC established medical instrumentation vocational education group with large government enterprises, foreign capital and joint venture enterprises, relevant industry associations and top hospitals and other units, formed the platform for national medical surveillance research. It made the innovation of cultivation model of the linkage of "industry, school, hospital, supervision and research". It has irreplaceable functions of cultivating scarce highskilled medical device talents for China. It has built the national medical instruments technology and regulatory personnel training base, nearly five years 10360 people have been trained from the industry and the social service training.

In short, the strategy development model building improves the technical service ability and promotes the development of SMIC. Student employment rate of SMIC is as high as $98 \%$ and $20 \%$ graduates go to universities or go to study abroad every year. Only in 2013, SMIC students take part in the national competition and win 9 of the first prize, 8 of the second prize and 4 of the third prize at the national level and win 51 honors in Shanghai provincial too. It has made a contribution to develop the modern medical instrumentation education system and received good results in practice of the development pattern.

\subsection{Other key points}

In our operating of this pattern, also need to deal with some relations in the practice. For example: how to position HVE accurately under the background of international economic development with medical instruments industry advantage and characteristic, how to achieve real economic cooperation with the enterprises and industry, how to strengthen higher vocational college by integrated into the international localization characteristics; how to develop HVE for perfecting the multi-level vocational education system of our country in internationalization, and so on.

\section{CONCLUSION}

It has important practical meaning to research the strategic development pattern of higher vocational education based on the ecological Niche Theory. It riches and perfects the theory of the internationalization of $\mathrm{HVE}$ and explores the development road of internationalization in higher vocational college too. At the same time, it also provides a pattern of HVE development in broadening the research object and scope of the extension and depth. However it can help us seeking and summarizing the countermeasures facing the 
vocational college career and succeeding in finding concise experience and achievements for promoting and perfecting the theory and practice of the internationalization of HVE development in our country. The research results have important theoretical significance and reference value on the practice of vocational training internationalized talents.

This paper is supported by Innovation Program of Shanghai Municipal Education Commission and is a part of the achievement from the key project: Research into the Development Pattern of Vocational Education on Medical Instruments in Internationalization (14ZS167).

\section{REFERENCES}

[1] Liang Li, Xiaotong Guan, Xiaolin Bai. Talk about the importance of college-enterprise cooperation in higher vocational education, LIAONING Higher Vocational Technical Institute Journal, Vol.10, 2008.

[2] Feng Chen. Interpretation of the modern vocational education system construction plan (2014-2020)", China. http://www.tech.net.cn/, 2014.

[3] Zhongwen $\mathrm{Yu}$. Times Call for Vocational Education Ver.3.0, China Youth. http://zqb.cyol.com/, 2013.

[4] Yuanguo Jiang, Xinwen Chen. The Functions of Higher Vocational Colleges, The Journal of Xiangfan Vocational and Technical College, vol.4, 2003.

[5] Forest J.J.F., Altbach, P.G. (ed). International Handbook of Higher Education. London: 2006.

[6] Ping Guan. The establishment of the vocational education state-led model - re-recognition of university-enterprise cooperation and work-integrated learning, China's higher education research, vol.6, 2013.

[7] Guanqun Wang. The survival and development of higher vocational education in the perspective of niche theory, Journal of Jiangsu teachers university of technology, vol.23, 2008. 